\title{
Minimally Invasive Open Reduction and Internal Fixation for Osteoporotic Vertebral Compression Fractures: Technical Report and Mid-Term Outcomes
}

\author{
Jui-Yang Hsieh1, Po-Quang Chen2,3, Jyh-Horng Wang2 \\ ${ }^{1}$ Department of Orthopedics, National Taiwan University Hospital and Jinshan Branch, Taiwan \\ ${ }^{2}$ Department of Orthopedics, National Taiwan University Hospital, Taiwan \\ ${ }^{3}$ Department of Orthopedics, Min-Sheng General Hospital, Taiwan \\ Email: ^ocean_x5@yahoo.com.tw, chen.poquang@gmail.com,jhwang@ntuh.gov.tw
}

How to cite this paper: Hsieh, J.Y., Chen, P.-Q. and Wang, J.-H. (2018) Minimally Invasive Open Reduction and Internal Fixation for Osteoporotic Vertebral Compression Fractures: Technical Report and Mid-Term Outcomes. Open Journal of Orthopedics, 8, 337-350.

https://doi.org/10.4236/ojo.2018.89037

Received: May 5, 2018

Accepted: September 16, 2018

Published: September 19, 2018

Copyright $\odot 2018$ by authors and Scientific Research Publishing Inc. This work is licensed under the Creative Commons Attribution International License (CC BY 4.0).

http://creativecommons.org/licenses/by/4.0/

(c) (i) Open Access

\begin{abstract}
Background: Traditional open instrumentation may cause surgical complications due to fragile bones and induce medical comorbidities in senile patients. Vertebroplasty and kyphoplasty are palliative augmentation procedures that have been associated with increased risks of cement leakage, adjacent fractures and non-union. Objective: The aim of this study was to describe a novel approach for the union of osteoporotic vertebral compression fractures with minimally invasive open reduction and internal fixation. Patients and Methods: Seven consecutive patients with intractable back pain without neurological deficits due to osteoporotic vertebral compression fractures were treated using minimally invasive fixation with intra-vertebral expandable pillars and artificial bone substitute. The clinical symptoms and image findings were recorded. Results: All of the patients reported relief of back pain, and the height of the vertebral bodies was well restored. X-ray findings obtained 2 to 4 years after the procedures showed fracture healing and favorable formation of the callus confirmed in the anterior longitudinal ligament. Conclusion: This mini-open procedure with intravertebral devices is an effective and reliable technique for osteoporotic vertebral compression fractures and may avoid complications related to traditional open spinal instrumentation procedures and augmentation with bone cement.
\end{abstract}

\section{Keywords}

Osteoporotic Vertebral Compression Fracture, Minimally Invasive Spine 
Surgery, Intra-Vertebral Expandable Pillar, Fracture Union, Bone Cement

\section{Introduction}

Osteoporotic vertebral compression fractures (OVCF) can cause extreme disability and morbidity in elderly people, and can be difficult to treat due to poor bone quality [1]. Open posterior long segment instrumentation and fusion are the traditional methods to repair vertebral fractures and correct kyphotic deformities [2] [3]. However, traditional open instrumentation with or without fusion can cause major complications including medical comorbidities due to a long operation time, extensive operative wounds, more blood loss, pulling out and subsidence of implants in fragile osteoporotic bones, and non-union of fractures [4] [5].

Percutaneous vertebroplasty and balloon kyphoplasty can swiftly relieve back pain by providing mechanical support with bone cement [6] [7]. However, polymethyl methacrylate (PMMA)-related complications include cement leakage, pulmonary embolism, neurologic compromise and infection [8] [9] [10] [11]. Over the long-term, bone cement leads to non-union due to osteolysis from the release of toxic monomers with PMMA debris, and intervertebral disc degeneration with adjacent vertebral fracture due to the stress-shielding from the inadequate mechanical strength [12] [13] [14] [15] [16].

We recently introduced an intra-vertebral expandable pillars (I-VEPs) procedure, and demonstrated that it is effective in reducing collapsed vertebra and in providing fitting fixation for injured vertebra [17]. Posterior short-segment fixation with I-VEPs is an alternative procedure to relieve symptomatic local back pain and avoid a global domino effect in an osteoporotic kyphotic spine [18].

The aim of this study was to describe our experience with minimally invasive spine surgery (MISS) for the serial restoration of collapsed vertebra. The procedures included insertion of I-VEPs and artificial bone substitute in osteoporotic patients without neurological deficits. The aims of the procedures were to avoid the detrimental effects of excessive open surgery and long fixation segments or PMMA-related complications, and also to provide mid-term outcomes of fracture union and pain relief.

\section{Patients and Methods}

\subsection{Patient Population}

This is a retrospective study of a consecutive series of seven patients with OVCFs without neurological deficits or spinal cord compromise. They were treated using MISS open reduction and internal fixation (ORIF) using insertion of guide pin-assisted I-VEPs (Aaxter Pillar Vertebral Spacer, Aaxter Co., Ltd, Taipei, ROC) and artificial bone substitute (PRO-DENSE ${ }^{\text {ma }}$, Wright Medical Technology, Arlington, TN, USA) by the same surgeon from December 2013 to April 2015. In this retrospective study, the variables were included gender, age, the 
level and type of fractures and bone mineral density (BMD). The demographic data, clinical VAS for pain, and radiological findings are summarized in Table 1

[19]. Radiographic outcomes were assessed by measuring the anterior vertebral body height and local kyphotic angle (Figure 1). The patients included four women and three men, with an average age of 78 years (range 63 to 88 years). The location of the OVCFs was distributed mainly at the thoraco-lumbar junction. With regards to the BMD of the lumbar spine, five cases were osteoporotic and the other two were osteopenia. A visual analogue scale pain score (VAS) and Oswestry disability index (ODI) revealed severe back pain in all of the patients. The Research Ethics Committee of National Taiwan University Hospital has approved this investigation.

\subsection{Surgical Technique}

The procedures were performed in the prone position over a C-arm fluoroscopic table with supportive chest and pelvic pads. Under intravenous general anesthesia with moderate conscious sedation, the patient could provide continuous feedback. This enabled the operator to estimate neurological symptoms and signs in real time to avoid injuring the neural structures. The operative tools are shown in Figure 2.

The location of the vertebral fractures was first outlined by lateral fluoroscopy. After identifying the index pedicle, which was generally located approximately 2 $\mathrm{cm}$ lateral to the midline in anteroposterior fluoroscopy, additional local anesthetic was administered over the skin and subcutaneous layer. A stab skin incision about $2 \mathrm{~cm}$ in length was made for access. A dissection plane similar to the Wiltse paraspinal muscle-splitting approach was developed between the multifidus and longissimus muscles under blunt dissection and manual palpation of the transverse process and pedicles. A cannulated trocar awl was used to palpate the proper position of the entry point, the junction of the midpoint of the lumbar transverse process with the lateral aspect of the superior articulating facet. It is important to confirm this step with radiographic fluoroscopy before probing the pedicle because of the limited visualization, particularly for surgeons with limited experience.

The awl tip was used to cut into the cortex bone and probe the pedicle tract manually, preferably to the center of the vertebral body on lateral view. A 1.0-mm guide wire was then passed through the trocar to replace the awl. After removal of the trocar, a 4-mm cannulated dilator was gently knocked into place via the guide wire until it was $3 \mathrm{~mm}$ away from the anterior cortex of the vertebrae as monitored by fluoroscopy. I-VEP passage was prepared and subsequently dilated using a custom-made serial dilator through the guide wire, which allowed the cancellous wall of the pedicle tract and collapse of the vertebral fracture to be more sealed off and compacted. Dilatation was serially performed until it was $8 \mathrm{~mm}$ or $9 \mathrm{~mm}$ in diameter to allow for adequate reduction of the collapsed vertebrae. 
Table 1. Patients' demographic and operative data.

\begin{tabular}{|c|c|c|c|c|c|c|c|c|c|c|c|c|c|c|}
\hline \multirow{2}{*}{ No. } & \multirow{2}{*}{ Sex } & \multirow{2}{*}{$\begin{array}{c}\text { Age } \\
\text { (years) }\end{array}$} & \multirow{2}{*}{ Level } & \multirow{2}{*}{ Type* } & \multirow{2}{*}{ BMD } & \multicolumn{4}{|c|}{ Pre-OP } & \multicolumn{4}{|c|}{$\begin{array}{l}\text { Post-OP } \\
\text { (6 months) }\end{array}$} & \multirow{2}{*}{$\begin{array}{l}\text { Follow-up } \\
\text { (months) }\end{array}$} \\
\hline & & & & & & VAS & $\mathrm{AH}(\mathrm{mm})$ & $\begin{array}{l}\mathrm{KA} \\
\left({ }^{\circ}\right)\end{array}$ & ODI & VAS & $\mathrm{AH}(\mathrm{mm})$ & $\begin{array}{l}\mathrm{KA} \\
\left({ }^{\circ}\right)\end{array}$ & ODI & \\
\hline 1 & $\mathrm{~F}$ & 79 & T12 & $\mathrm{W}-2$ & -3.07 & 9 & 16.4 & 15.2 & 48 & 1 & 19.3 & 11.8 & 16 & 45 \\
\hline 2 & M & 76 & T12 & $\mathrm{W}-3$ & -1.54 & 9 & 10.8 & 26.9 & 38 & 1 & 16.0 & 17.1 & 28 & 43 \\
\hline 3 & M & 82 & L4 & $\mathrm{W}-1$ & -1.05 & 8 & 15.5 & 8.6 & 60 & 2 & 25.2 & 1.9 & 18 & 49 \\
\hline 4 & F & 79 & $\begin{array}{l}\text { T12 } \\
\text { L1 }\end{array}$ & $\begin{array}{l}\text { W-1 } \\
\text { B-2 }\end{array}$ & -3.2 & 9 & $13.8,19.5$ & $5.6,13.3$ & 56 & 3 & $17.9,22.2$ & $8.2,8.7$ & 20 & 40 \\
\hline 5 & M & 88 & L1 & B-3 & -2.8 & 8 & 16.8 & 17 & 50 & 1 & 23.0 & 7.4 & 16 & 24 \\
\hline 6 & F & 63 & L1 & B-3 & -1.3 & 9 & 13.2 & 20.2 & 46 & 2 & 17.2 & 14.8 & 18 & 47 \\
\hline 7 & F & 78 & T12 & W-3 & -3.5 & 9 & 5.4 & 20.1 & 58 & 1 & 10.9 & 10.8 & 28 & 36 \\
\hline Averaged & & 78 & & & -2.35 & 9 & 13.0 & 13.0 & 51 & 2 & 18.6 & 10.6 & 21 & 41 \\
\hline
\end{tabular}

${ }^{*} \mathrm{~W}$ : wedge; B: biconcave; C: crush. 1: mild (20\% - 25\% height loss); 2: moderate (25\% - 40\% height loss); 3: severe ( $>40 \%$ height loss) [19]. AH $=$ anterior vertebral body height; KA = kyphotic angle; VAS = visual analogue scale pain score; ODI = Oswestry disability index with 0 - 20 of minimal disability; 21 40 of moderate disability; 41 - 60 of severe disability; $61-80$ of cripple and 81 - 100 of bed-bound or exaggerating their symptoms [20] [21].

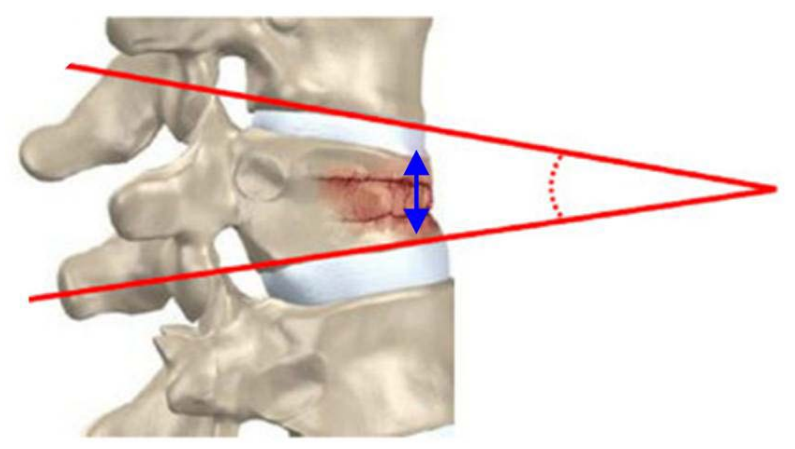

Figure 1. Schematic diagram of radiographic measurements. The anterior vertebral body height $(\mathrm{AH})$ of the fractured vertebra (blue double arrow) was the actual height of the anterior cortex of the vertebral body as measured on a lateral radiograph. Measuring on a lateral radiograph with a modified Cobb method (red dotted angle) required inferior endplates above the fractured vertebra to measure the kyphotic angle (KA) [12].

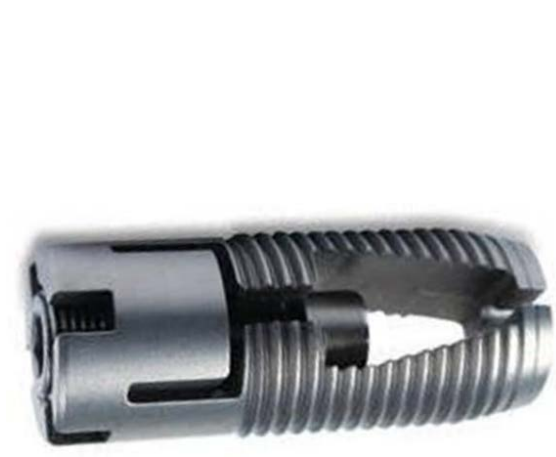

(a)

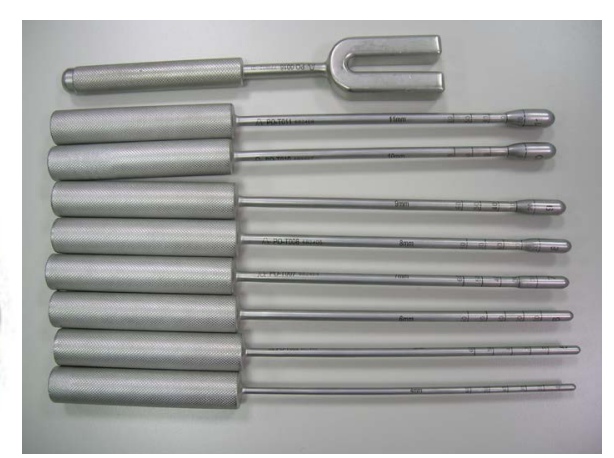

(b) 


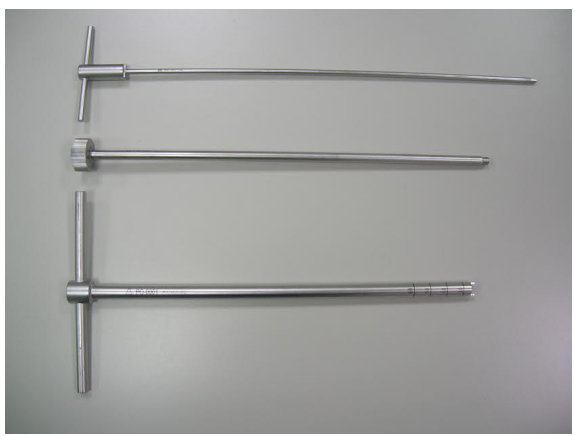

(c)

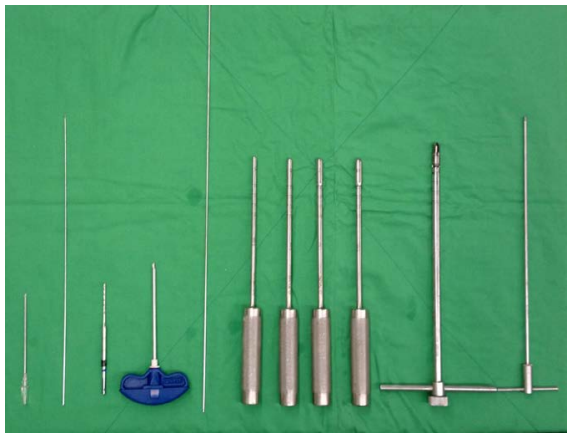

(e)

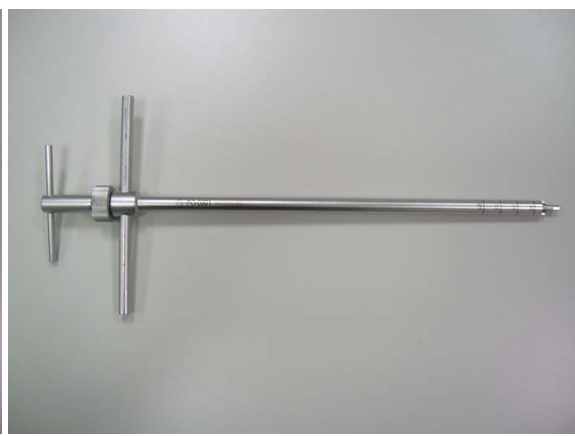

(d)

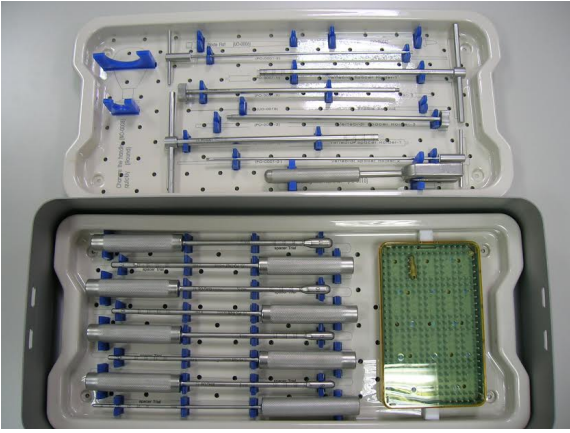

(f)

Figure 2. The tools for I-VEP. (a) Cylindrical type of Pillar. (b) Tract dilatation kit, diameter from $4 \mathrm{~mm}$ to $11 \mathrm{~mm}$. (c)-(d) Screw-in dilator, Pillar holder and working cannula are shown in sequence from the top in Figure 2(c) and its combination in 2(d). (e) All tools in one set. (f) The tools used for MISS ORIF for OVCF with I-VEP.

When bipedicular access had been obtained, the trocar was placed into the vertebrae via the guide wire, and $2 \mathrm{ml}$ to $5 \mathrm{ml}$ of artificial bone substitute $\left(\mathrm{PRO}^{-D E N S E}{ }^{\mathrm{Tu}}\right)$ was injected on each side. One I-VEP was screwed into the vertebra through the same pedicle tract using a holding handle. This could be expanded by $3^{\circ}$ to $4^{\circ}$ after fastening the inner screw into the conical cavity through the holding handle using a customized I-VEP screwdriver. Another I-VEP was inserted after injecting the artificial bone substitute on the other side. The fully expanded I-VEPs were then disconnected from the holding handle after ensuring good positioning of the concentric implants in the central vertebrae for good restoration of vertebral height.

\section{Results}

We tried to make the wounds and blood loss minimum. All of the patients were discharged from hospital at post-operative day 2 to 4 , and were encouraged to wear an extension back brace for at least 3 months. Before surgery, the average VAS and ODI scores were 8.7 and 50.9, respectively. At the 6-month follow-up visit, the average VAS and ODI scores had decreased to 1.6 and 20.6, respectively. The anterior height increased from $13.0 \mathrm{~mm}$ to $18.6 \mathrm{~mm}$, and the local kyphotic angle decreased from $18.0^{\circ}$ pre-operatively to $10.6^{\circ}$ after 3 months. The closed follow-up period was within 6 months and then the regular follow-up pe- 
riod ranged from 2 to 4 years. The details are summarized in Table 1 . None of the patients experienced neurological deficits or wound infections during the peri- or post-operative period, and none of the patients required analgesics. Anti-osteoporotic agents of alendronate or denosumab were prescribed as well as calcium supplements after surgery, and gentle exercise was also encouraged.

Illustrative case 1

This 82-year-old male (Case 3) presented with the chief complaint of disability from low back pain (VAS $=8$ and ODI $=60$ ). On neurological examination, he did not have muscle weakness of lower limb or sciatica. Radiography, magnetic resonance imaging and whole body bone scintigraphy assessments revealed a sub-acute compression fracture in the L4 vertebral body. After discussing all of the treatment options and the number of united levels, he underwent MISS ORIF with I-VEPs and supplementary artificial bone substitute at the L4 level. His back pain had completely resolved at the 1-month follow-up visit. He had an uneventful postoperative course and was free from back pain with almost complete union noted on radiography at the 6-month follow-up visit. Moreover, there was progressively increasing abundant bony callus formation at the L4 vertebral body at the post-operative 4 -month and 28 -month follow-up visits (Figure 3).

Illustrative case 2

This 79-year-old female (Case 1) had osteoporosis (bone mineral density, $\mathrm{T}=$ -3.07 at the L-spine and $\mathrm{T}=-3.4$ at the right hip) and a T12 OVCF. MISS ORIF with I-VEPs and supplementary artificial bone substitute were implanted precisely with good alignment. Her back pain had completely resolved at the 3-month follow-up visit. She had an uneventful postoperative course and was neurologically intact with complete union noted on radiography at the 20-month follow-up visit (Figure 4).

Illustrative case 3

This 63-year-old female (Case 6) had an OVCF at the L1 level. She received MISS ORIF with I-VEPs and supplementary artificial bone substitute and experienced gradual relief of the back pain in the following 2 months. The spinal canal compromise was maintained at about $30 \%$ before and after surgery. Radiography showed abundant bony callus with union at the fractured vertebrae at the 27-month follow-up visit. However, migration of the two dislodged I-VEPs without any neurological deficits was noted. She then had an uneventful postoperative course and was neurologically intact at the final 47-month follow-up visit (Figure 5).

\section{Discussion}

Treatment for patients with fragile and OVCFs is controversial and challenging.

Various techniques have been proposed to stabilize the spine, and debate continues as to which is the most beneficial and whether a posterior approach alone is better than an anterior approach or a combined approach. Similar discussions 


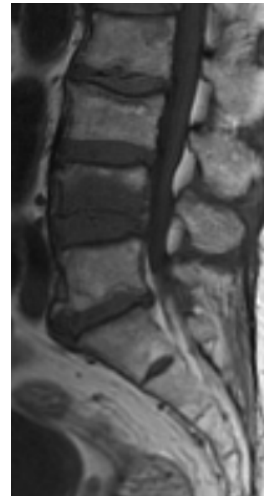

(a)

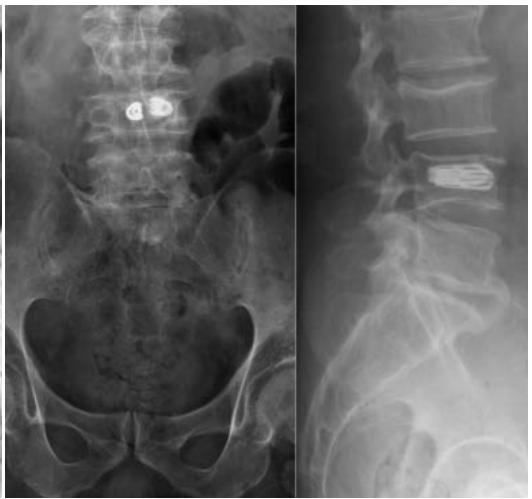

(b)

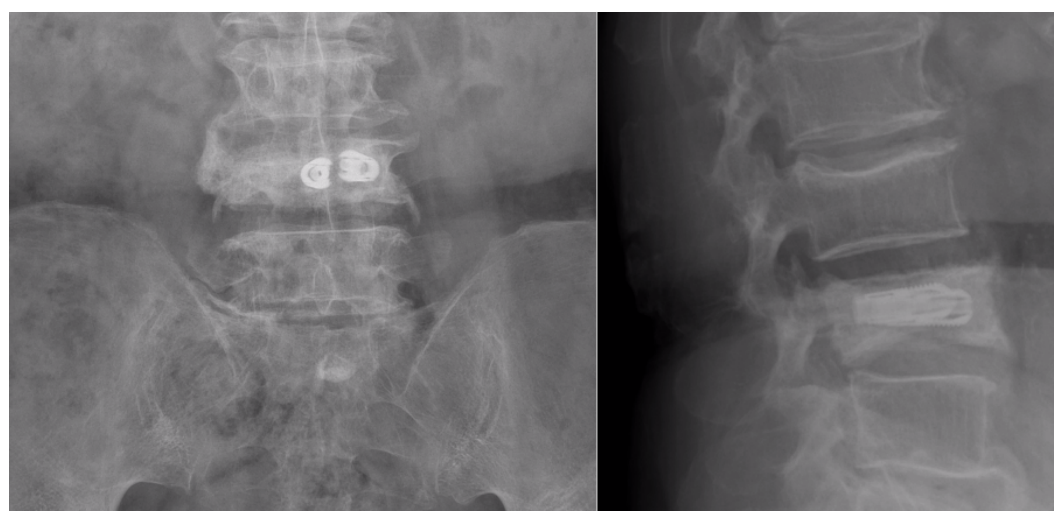

(c)

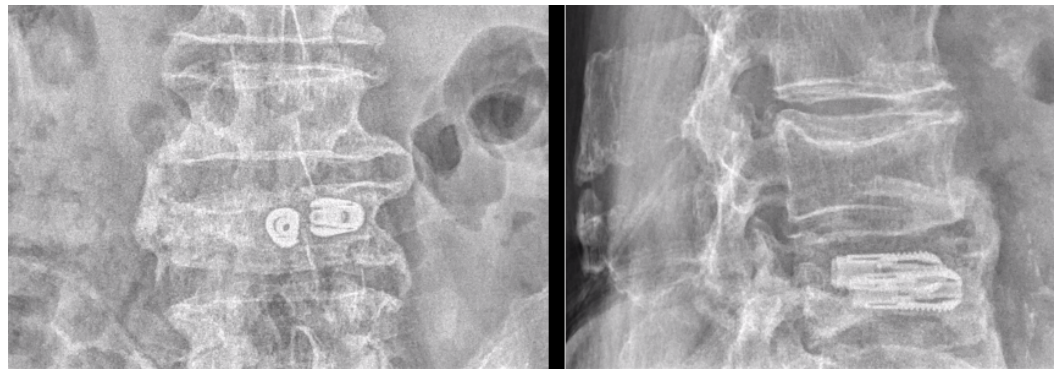

(d)

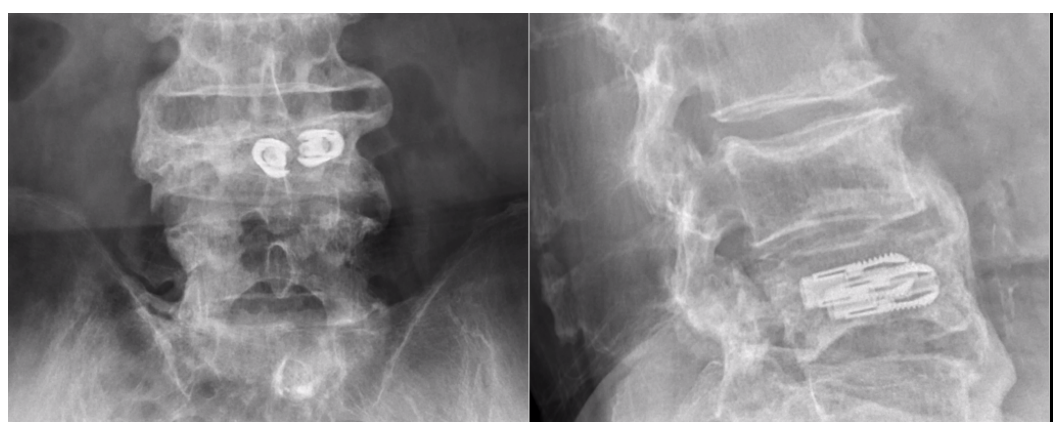

(e)

Figure 3. (a) Magnetic resonance image of patient 3 before surgery showing wedge deformity with a sub-acute benign compression fracture with bone marrow edema at the L4 vertebral body. (b)-(e) Radiograph showing progressively increasing abundant bony callus formation at the L4 vertebral body 1 day, 6 months, 14 months and 28 months post-operatively. 


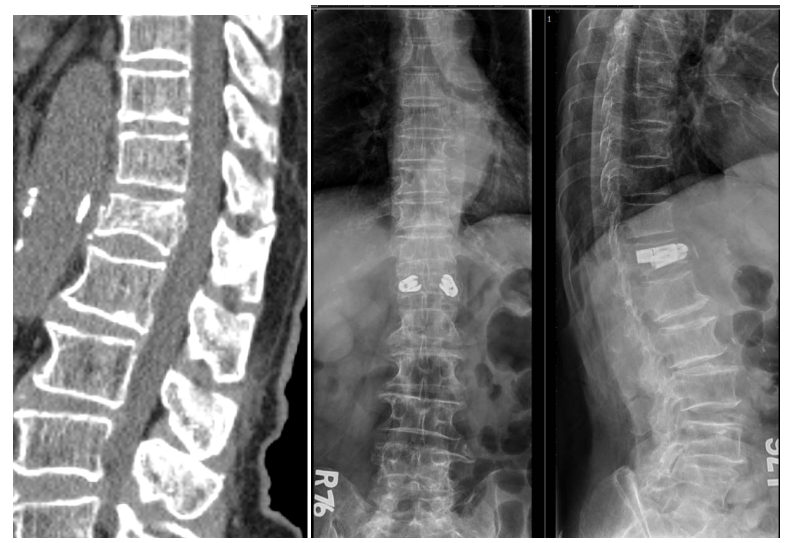

(a)

(b)

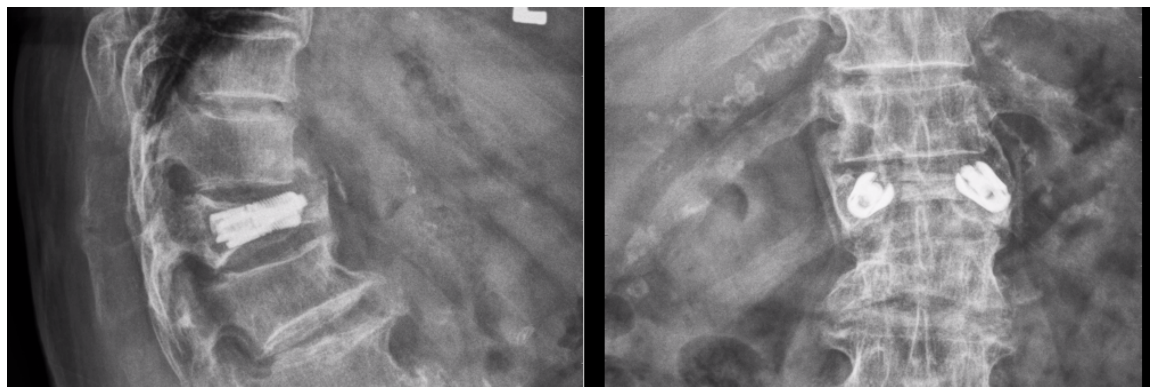

(c)

Figure 4. (a) Computed tomography scans showing a fragile collapse at T12. (b) Radiograph showing good alignment of the implants at post-operative day 1. (c) Radiograph showing abundant bony callus and nearly complete union after 20 months.

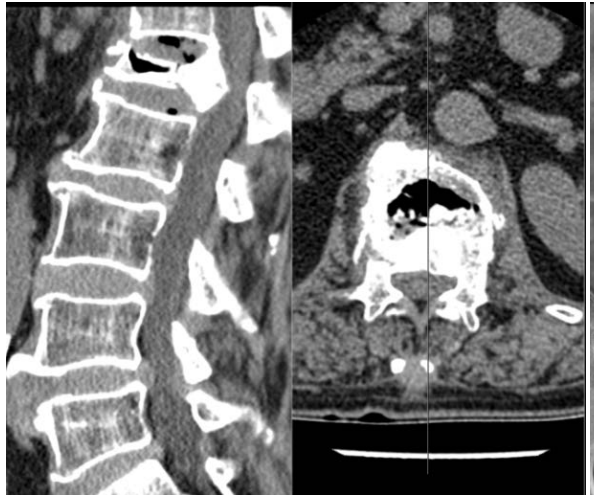

(a)

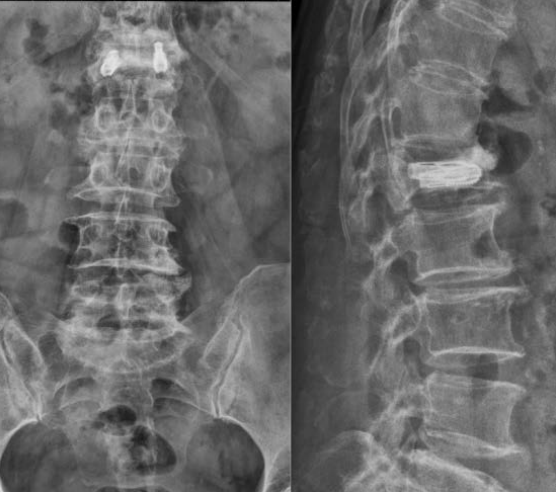

(b)

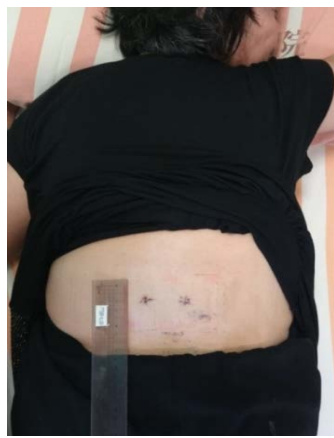

(c)

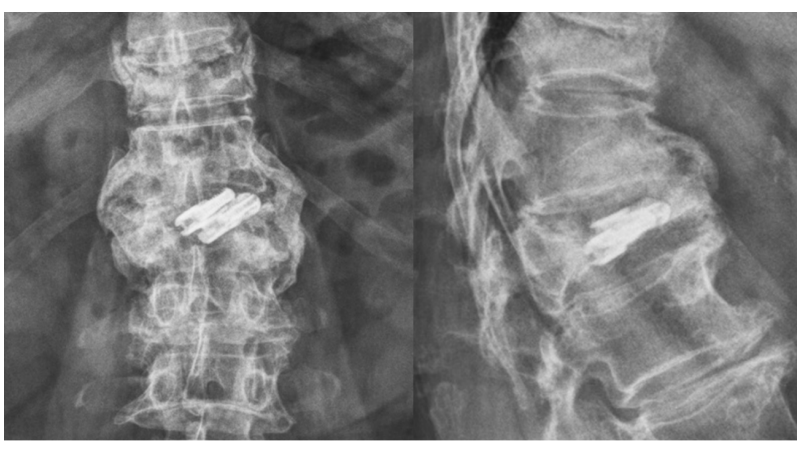

(d) 


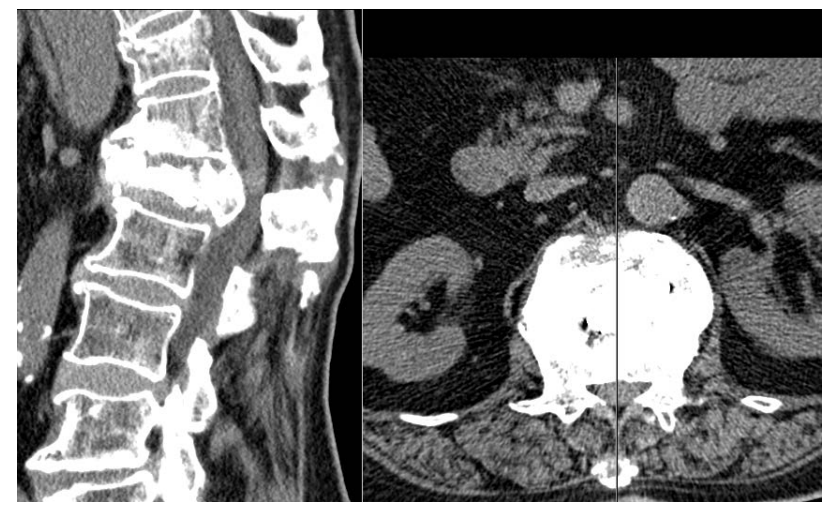

(e)

Figure 5. (a) Computed tomography scans of patient 6 showing a vacuum phenomenon and biconcave collapse with spinal canal compromise of approximately $30 \%$ at L1. (b) Radiograph showing good alignment of the implants at post-operative day 1 . (c) Photograph showing minimal incision wounds before removal of the stitches after 2 weeks. (d) Radiograph showing favorable formation of the callus confirmed in the anterior longitudinal ligament with complete union after 27 months. However, migration of two dislodged I-VEPs was noted. (e) Computed tomography scan showing intraosseous implantation with the same spinal compromise at 27 months.

about fusion or non-fusion, whether or not to use interbody fusion, and cage design are also on-going.

Traditionally, long segment fixation has been used for burst fractures, even for an osteoporotic spine. However, a prolonged operation time is possible, along with the potential side effects of excessive blood loss, pseudarthrosis or adjacent segmental degeneration [4] [22]. Segmental fixation and interbody fusion may be reserved for unstable vertebral fractures, neurological deficits or sagittal imbalance. Considering that preservation of the motion of segments is important after treatment for OVCF. It should be unnecessary in segmental fixation across non-injured vertebrae for a patient with a benign OVCF without neurological deficits.

The concept of good reduction, rigid internal fixation and preservation of the motion of joints in long bone fractures could potentially be applied to vertebral compression fractures. After failed conservative treatment, surgical strategies for uncomplicated vertebral compression fractures currently mainly involve ORIF using intra-vertebral devices combined with bone grafting. The I-VEP plus artificial bone substitute for MISS, as used in this study, may restore the collapsed vertebral body and maintain spinal motion in patients with an osteoporotic kyphotic spine.

Bone cement injections were firstly applied in a patient with a symptomatic C2 hemangioma in the mid-1980s [23]. In the past three decades, percutaneous vertebroplasty has gradually gained popularity as a safe and effective technique to achieve immediate pain relief and improve the quality of life for old patients with OVCF [24] [25]. In recent years, balloon kyphoplasty and vesselplasty have gradually replaced it due to a reduced risk of cement leakage [26] [27]. However, 
other cement complications still remain in addition to cement leakage, including non-union of fractures and adjacent segmental fractures, and concerns have been raised as to its benefits [28] [29] [30] [31] [32]. PMMA is inert and non-biodegradable, which may influence the rate of bone remodeling by affecting bone metabolism and weakening the trabeculae by changing the mechanical environment [33] [34]. Thus, it has been suggested that cement augmentation should only be used in elderly patients with severe osteoporosis or limited life expectancy [35] [36] [37]. In other words, cementing should be treated as an augmentation technique and not as a gold standard for the permanent treatment of fractures.

I-VEPs are made of titanium alloy due to its excellent biocompatibility and are designed as a hollow threaded cylinder filled with autologous bone graft. After good open reduction with adequate serial dilatation, the biological intra-vertebral body fixation of an I-VEP is used to reconstruct the compressed vertebra through internal mechanical support, and bony fusion is encouraged with enveloped bone chips [17] [18]. PRO-DENSE ${ }^{\mathrm{Tm}}$, a fully synthetic composite material made from calcium sulphate $\left(\mathrm{CaSO}_{4}\right)$ and calcium phosphate $\left(\mathrm{CaPO}_{4}\right)$, is strong composite-like bone cement with good bone regeneration capacity [38] [39]. We used injections of PRO-DENSE ${ }^{\mathrm{m}}$ in this study instead of autologous bone chips because of the small operative wound field for placing bone chips and to reduce comorbidities from harvesting autologous bone.

The cause of migration in Illustrative case 3 may be the severe vacuum of vertebral fracture, inadequate bone substitute supplemented or the smaller size of I-VEP implanted. We should supplement more abundant bone substitute after implanting larger size of I-VEP if encountering a severe vacuum of OVCF. In such cases, open fixation with augmented pedicle screws to the adjacent segments may be feasible.

In this study, we tried to promote union of the vertebral compression fractures with open reduction using serially enlarged dilatations, and internal fixation of the I-VEP and artificial bone substitute. This procedure was effective and safe for vertebral compression fractures. Further long-term prospective studies with larger series are needed to assess the effectiveness of this technique.

As for the limitation of the current study, one was that the number of patients was too small. The other was the study was a single arm study design. For a more realistic setting, future studies should include comparisons with kyphoplasty with a larger sample size and observe the long-term outcomes.

\section{Conclusion}

Minimally invasive open reduction and internal fixation with I-VEPs and artificial bone substitute is an effective and feasible procedure for union in patients with vertebral compression fractures. It allows for the preservation of motion in non-pathological segments and promotes fracture healing with good reduction and rigid fixation without the need for non-biodegradable cement augmentation. 


\section{Author's Contribution}

All the authors contributed to the writing of this manuscript, and had read and approved the final version.

\section{Conflicts of Interest}

The authors state that there is no conflict of interest. The patient was informed and gave contentment for this article.

\section{References}

[1] Patil, S., Rawall, S., Singh, D., Mohan, K., Nagad, P., Shial, B., Pawar, U. and Nene, A. (2013) Surgical Patterns in Osteoporotic Vertebral Compression Fractures. European Spine Journal, 22, 883-891. https://doi.org/10.1007/s00586-012-2508-4

[2] Khan, K.M., Bhatti, A. and Khan, M.A. (2012) Posterior Spinal Fixation with Pedicle Screws and Rods System in Thoracolumbar Spinal Fractures. Journal of the College of Physicians and Surgeons Pakistan, 22, 778-782.

[3] Parker, J.W., Lane, J.R., Karaikovic, E.E. and Gaines, R.W. (2000) Successful Short-Segment Instrumentation and Fusion for Thoracolumbar Spine Fractures: A Consecutive 41/2-Year Series. Spine, 25, 1157-1170. https://doi.org/10.1097/00007632-200005010-00018

[4] Chotigavanich, C., Sanpakit, S., Wantthanaapisith, T., Thanapipatsiri, S. and Chotigavanich, C. (2009) The Surgical Treatment of the Osteoporotic Vertebral Compression Fracture in the Elderly Patients with the Spinal Instrumentation. Journal of the Medical Association of Thailand, 92, S109-S115.

[5] Fischer, C.R., Ducoffe, A.R. and Errico, T.J. (2014) Posterior Lumbar Fusion: Choice of Approach and Adjunct Techniques. Journal of the American Academy of Orthopaedic Surgeons, 22, 503-511. https://doi.org/10.5435/JAAOS-22-08-503

[6] Yimin, Y., Zhiwei, R., Wei, M. and Jha, R. (2013) Current Status of Percutaneous Vertebroplasty and Percutaneous Kyphoplasty-A Review. Medical Science Monitor, 19, 826-836. https://doi.org/10.12659/MSM.889479

[7] Ma, X.L., Xing, D., Ma, J.X., Xu, W.G., Wang, J. and Chen, Y. (2012) Balloon Kyphoplasty versus Percutaneous Vertebroplasty in Treating Osteoporotic Vertebral Compression Fracture: Grading the Evidence through a Systematic Review and Meta-Analysis. European Spine Journal, 21, 1844-1859. https://doi.org/10.1007/s00586-012-2441-6

[8] Mathis, J.M. (2003) Percutaneous Vertebroplasty: Complication Avoidance and Technique Optimization. American Journal of Neuroradiology, 24, 1697-1706.

[9] Venmans, A., Lohle, P.N., van Rooij, W.J., Verhaar, H.J. and Mali, W.P. (2008) Frequency and Outcome of Pulmonary Polymethylmethacrylate Embolism during Percutaneous Vertebroplasty. American Journal of Neuroradiology, 29, 1983-1985. https://doi.org/10.3174/ajnr.A1269

[10] Lee, M.J., Dumonski, M., Cahill, P., Stanley, T., Park, D. and Singh, K. (2009) Percutaneous Treatment of Vertebral Compression Fractures: A Meta-Analysis of Complications. Spine, 34, 1228-1232. https://doi.org/10.1097/BRS.0b013e3181a3c742

[11] Nussbaum, D.A., Gailloud, P. and Murphy, K. (2004) A Review of Complications Associated with Vertebroplasty and Kyphoplasty as Reported to the Food and Drug Administration Medical Device Related Web Site. Journal of Vascular and Interven- 
tional Radiology, 15, 1185-1192.

https://doi.org/10.1097/01.RVI.0000144757.14780.E0

[12] Quan, R., Ni, Y., Zhang, L., Xu, J., Zheng, X. and Yang, D. (2014) Short- and Long-Term Effects of Vertebroplastic Bone Cement on Cancellous Bone. Journal of the Mechanical Behavior of Biomedical Materials, 35, 102-110.

https://doi.org/10.1016/j.jmbbm.2014.03.007

[13] Pollintine, P., Dolan, P., Tobias, J.H. and Adams, M.A. (2004) Intervertebral Disc degeneration Can Lead to "Stress-Shielding" of the Anterior Vertebral Body: A Cause of Osteoporotic Vertebral Fracture? Spine, 29, 774-782. https://doi.org/10.1097/01.BRS.0000119401.23006.D2

[14] Zhao, H., Ni, C.F., Huang, J., Zhao, S.M., Gu, W.W., Jiang, H., Chen, L. and Tan, T.S. (2014) Effects of Bone Cement on Intervertebral Disc Degeneration. Experimental and Therapeutic Medicine, 7, 963-969.

https://doi.org/10.3892/etm.2014.1531

[15] Lin, W.C., Lee, Y.C., Lee, C.H., Kuo, Y.L., Cheng, Y.F., Lui, C.C. and Cheng, T.T. (2008) Refractures in Cemented Vertebrae after Percutaneous Vertebroplasty: A Retrospective Analysis. European Spine Journal, 17, 592-599.

https://doi.org/10.1007/s00586-007-0564-y

[16] Verlaan, J.J., Oner, F.C. and Dhert, W.J. (2006) Anterior Spinal Column Augmentation with Injectable Bone Cements. Biomaterials, 27, 290-301. https://doi.org/10.1016/j.biomaterials.2005.07.028

[17] Lee, H.H., Wu, S.S., Chuang, S.Y., Yeh, T.T. and Chen, P.Q. (2008) Biomechanical Evaluation of Transpedicularly Placed Intravertebral Support for the Management of Osteoporotic Vertebral Compression Fractures. Journal of Musculoskeletal Research, 11, 37-43. https://doi.org/10.1142/S0218957708001936 http://www.worldscientific.com/doi/abs/10.1142/S0218957708001936

[18] Hsieh, J.Y., Wu, C.D., Wang, T.M., Chen, H.Y., Farn, C.J. and Chen, P.Q. (2013) Reduction of the Domino Effect in Osteoporotic Vertebral Compression Fractures through Short-Segment Fixation with Intravertebral Expandable Pillars Compared to Percutaneous Kyphoplasty: A Case Control Study. BMC Musculoskeletal Disorders, 14, 75. https://doi.org/10.1186/1471-2474-14-75

[19] Genant, H.K., Wu, C.Y., van Kuijk, C. and Nevitt, M.C. (1993) Vertebral Fracture Assessment Using a Semiquantitative Technique. Journal of Bone and Mineral Research, 8, 1137-1148. https://doi.org/10.1002/jbmr.5650080915

[20] Fairbank, J.C. and Pynsent, P.B. (2000) The Oswestry Disability Index. Spine, 25, 2940-2952. https://doi.org/10.1097/00007632-200011150-00017

[21] Davidson, M. and Keating, J.L. (2002) A Comparison of Five Low Back Disability Questionnaires: Reliability and Responsiveness. Physical Therapy, 82, 8-24.

https://doi.org/10.1093/ptj/82.1.8

[22] Reinhold, M., Knop, C., Beisse, R., Audigé, L., Kandziora, F., Pizanis, A., Pranzl, R., Gercek, E., Schultheiss, M., Weckbach, A., Bühren, V. and Blauth, M. (2010) Operative Treatment of 733 Patients with Acute Thoracolumbar Spinal Injuries: Comprehensive Results from the Second, Prospective, Internet-Based Multicenter Study of the Spine Study Group of the German Association of Trauma Surgery. European Spine Journal, 19, 1657-1676. https://doi.org/10.1007/s00586-010-1451-5

[23] Galibert, P., Deramond, H., Rosat, P. and Le Gars, D. (1987) Preliminary Note on the Treatment of Vertebral Angioma by Percutaneous Acrylic Vertebroplasty. Neurochirurgie, 33, 166-168.

[24] Evans, A.J., Jensen, M.E., Kip, K.E., DeNardo, A.J., Lawler, G.J., Negin, G.A., Rem- 
ley, K.B., Boutin, S.M. and Dunnagan, S.A. (2003) Vertebral Compression Fractures: Pain Reduction and Improvement in Functional Mobility after Percutaneous Polymethylmethacrylate Vertebroplasty Retrospective Report of 245 Cases. Radiology, 226, 366-372. https://doi.org/10.1148/radiol.2262010906

[25] Chandra, R.V., Yoo, A.J. and Hirsch, J.A. (2013) Vertebral Augmentation: Update on Safety, Efficacy, Cost Effectiveness and Increased Survival? Pain Physician, 16, 309-320.

[26] Garfin, S.R., Yuan, H.A. and Reiley, M.A. (2001) New Technologies in Spine: Kyphoplasty and Vertebroplasty for the Treatment of Painful Osteoporotic Compression Fractures. Spine, 26, 1511-1515. https://doi.org/10.1097/00007632-200107150-00002

[27] Klingler, J.H., Sircar, R., Deininger, M.H., Scheiwe, C., Kogias, E. and Hubbe, U. (2013) Vesselplasty: A New Minimally Invasive Approach to Treat Pathological Vertebral Fractures in Selected Tumor Patients-Preliminary Results. Rofo, 185, 340-350. https://doi.org/10.1055/s-0032-1330443

[28] Buchbinder, R., Osborne, R.H., Ebeling, P.R., Wark, J.D., Mitchell, P., Wriedt, C., Graves, S., Staples, M.P. and Murphy, B. (2009) A Randomized Trial of Vertebroplasty for Painful Osteoporotic Vertebral Fractures. The New England Journal of Medicine, 361, 557-568. https://doi.org/10.1056/NEJMoa0900429

[29] Kallmes, D.F., Comstock, B.A., Heagerty, P.J., Turner, J.A., Wilson, D.J., Diamond, T.H., Edwards, R., Gray, L.A., Stout, L., Owen, S., Hollingworth, W., Ghdoke, B., Annesley-Williams, D.J., Ralston, S.H. and Jarvik, J.G. (2009) A Randomized Trial of Vertebroplasty for Osteoporotic Spinal Fractures. The New England Journal of Medicine, 361, 569-579. https://doi.org/10.1056/NEJMoa0900563

[30] Staples, M.P., Kallmes, D.F., Comstock, B.A., Jarvik, J.G., Osborne, R.H., Heagerty, P.J. and Buchbinder, R. (2011) Effectiveness of Vertebroplasty Using Individual Patient Data from Two Randomised Placebo Controlled Trials: Meta-Analysis. BMJ, 343, d3952. https://doi.org/10.1136/bmj.d3952

[31] Hussain, A. and Erdek, M. (2013) Vertebroplasty Augmentation Procedures: Examining the Controversy. Pain Physician, 16, E483-E490.

[32] Liu, J., Li, X., Tang, D., Cui, X., Li, X., Yao, M., Yu, P., Qian, X., Wang, Y. and Jiang, H. (2013) Comparing Pain Reduction Following Vertebroplasty and Conservative Treatment for Osteoporotic Vertebral Compression Fractures: A Meta-Analysis of Randomized Controlled Trials. Pain Physician, 16, 455-464.

[33] Kalfas, I.H. (2001) Principles of Bone Healing. Neurosurgical Focus, 10, E1. https://doi.org/10.3171/foc.2001.10.4.2

[34] Belkoff, S.M., Mathis, J.M., Jasper, L.E. and Deramond, H. (2001) The Biomechanics of Vertebroplasty. The Effect of Cement Volume on Mechanical Behavior. Spine, 26, 1537-1541. https://doi.org/10.1097/00007632-200107150-00007

[35] Gupta, R.K., Gupta, V. and Gupta, N. (2012) Outcomes of Osteoporotic Trochanteric Fractures Treated with Cement-Augmented Dynamic Hip Screw. Indian Journal of Orthopaedics, 46, 640-645. https://doi.org/10.4103/0019-5413.104193

[36] Plancarte, R., Guajardo, J., Meneses-Garcia, A., Hernandez-Porras, C., Chejne-Gomez, F., Medina-Santillan, R., Galindo-Hueso, G., Nieves, U. and Cerezo, O. (2014) Clinical Benefits of Femoroplasty: A Nonsurgical Alternative for the Management of Femoral Metastases. Pain Physician, 17, 227-234.

[37] Andresen, R., Radmer, S., Lüdtke, C.W., Kamusella, P., Wissgott, C. and Schober, H.C. (2014) Balloon Sacroplasty as a Palliative Pain Treatment in Patients with Metastasis-Induced Bone Destruction and Pathological Fractures. Rofo, 186, 881-886. 
https://doi.org/10.1055/s-0033-1356418

[38] Urban, R.M., Turner, T.M., Hall, D.J., Inoue, N. and Gitelis, S. (2007) Increased Bone Formation Using Calcium Sulfate-Calcium Phosphate Composite Graft. Clinical Orthopaedics and Related Research, 459, 110-117.

https://doi.org/10.1097/BLO.0b013e318059b902

[39] Civinini, R., De Biase, P., Carulli, C., Matassi, F., Nistri, L., Capanna, R. and Innocenti, M. (2012) The Use of an Injectable Calcium Sulphate/Calcium Phosphate Bioceramic in the Treatment of Osteonecrosis of the Femoral Head. International Orthopaedics, 36, 1583-1588. https://doi.org/10.1007/s00264-012-1525-6 